\title{
Urgences
}

\section{Jardin de rocaille en octobre}

\section{Liliane Le Grand et Robert Dehin}

Numéro 16, mars 1987

D.G. Jones : d'un texte, d'autres

URI : https://id.erudit.org/iderudit/025397ar

DOI : https://doi.org/10.7202/025397ar

Aller au sommaire du numéro

Éditeur(s)

Urgences

ISSN

0226-9554 (imprimé)

1927-3924 (numérique)

Découvrir la revue

Citer cette note

Le Grand, L. \& Dehin, R. (1987). Jardin de rocaille en octobre. Urgences, (16), 68-69. https://doi.org/10.7202/025397ar d'utilisation que vous pouvez consulter en ligne.

https://apropos.erudit.org/fr/usagers/politique-dutilisation/ 


\section{Liliane Le Grand/Robert Dehin JARDIN DE ROCAILLE EN OCTOBRE}

Sous la pluie, surgissent les ombres

d'une ruine; c'est ici

que gisent les fleurs mortes

Et les feuilles qui sont tombées

y rassemblent leurs couleurs. Pourtant

ce sont les pierres qui fleurissent

Comme une assemblée de livres

ou ceux qui ne sont plus

continuent de parler

De plus en plus j'ai la bouche

qui se remplit de pierres

et telles des fleurs

sont les os de mes collègues

Est-ce, le chaos, le paradis

ou bien Angkor Vat

ou peut-être la ville entre ses murs

lorsqu'il se fait tard?

Ce n'est ni vivant ni mort

ni même humain. J'y passe

sous la pluie, comme une ombre.

C'est une floraison de runes 


\section{Les problèmes de traduction}

Le problème des demi-rimes et autres effets spéciaux (jeu de mots...) ne s'est pas vraiment posé car il s'agissait avant tout d'écrire en français et de se soumettre aux valeurs esthétiques propres à cette langue.

Dans la poésie française l'allitération et l'assonance ne peuvent être utilisées aussi librement que dans la poésie anglaise. De tels effets, s'ils sont trop gratuits, sans relation avec le sens descriptif de la phrase, sont à éviter autant que possible. (Certains de ces effets n'ont cependant posé aucun problème: ruin/runes par exemple - une distance suffisante les sépare. Par ailleurs, il eut été forcé de vouloir rendre l'identité des consonnes d'attaques des temps forts de la première phrase: rain/ruin. Ou celle qu'on retrouve dans «More and more my mouth" qui est un vers allitératif du type pratiqué dans l'ancienne poésie anglaise.)

Ainsi donc, notre but a surtout été de rendre le plus conformément possible le sens et l'atmosphère, mais aussi le rythme du poème original.

Dans la structure rythmique du poème original on retrouve principalement, en fait de pieds rythmiques, des anapestes (..-) et des iambes (.-). A cela rien d'étonnant: ce sont les plus utilisés dans la poésie anglaise.

Nous nous sommes efforcés de la reproduire en utilisant une rythmique impaire (le plus souvent 7 ou 5 ) et des groupes rythmiques de 2 ou 3 syllabes clairement prononcées (dans le vers libre et la prose cadencée on ne tient pas compte des syllabes composées d'un «e» muet ni même de "ent" des verbes à la 3ème personne du pluriel). 